\title{
Janny HC Leung The object of fidelity in translating multilingual legislation
}

\begin{abstract}
Should fidelity in legal translation be judged in terms of approximation to the source text? What are the possible alternatives? Multilingual jurisdictions see great needs in the translation of texts of the law and tend to be particularly concerned with the uniform application of the law in its different renditions. As a response to new sources of legal indeterminacy created by legal multilingualism, approaches to statutory interpretation in multilingual jurisdictions have shifted in focus. Through analyzing the way linguistic indeterminacy in legislation is resolved in various multilingual jurisdictions, I argue that an understanding of approaches to statutory interpretation can help translators better grasp the nature of the legislative texts they are dealing with and potentially illuminate strategies of legal translation.
\end{abstract}

Keywords: fidelity; indeterminacy; statutory interpretation; legal translation; multilingualism

\section{Legal translation, linguistic indeterminacy, and statutory interpretation}

In more areas than not, translators have no systematic access to reader reception of their work. Legal texts, however, are often interpreted in a transparent and open manner in courts by their primary receivers - lawyers and judges (whereas the general public may be seen as indirect receivers, see Šarčević 1997, 2000). With the process of reasoning being articulate and accessible, the interpretation and application of legal texts in courts constitute a wealth of informative data for

Janny HC Leung: University of Hong Kong. E-mail: janny@cantab.net 
the legal translator and provide a means of assessing how successful an authenticated translation ${ }^{1}$ is.

How legal texts are translated has a direct impact on the linguistic and legal indeterminacy of multilingual law, which in turn affects how the texts are interpreted. Legal indeterminacy has attracted a lot of attention from legal theorists, as it casts doubt on the extent to which the law controls judicial decisions, and thus threatens the legitimacy of the law. The indeterminacy thesis, a radical argument for legal realism, suggests that the judge often must choose between two or more legally acceptable solutions to a case; in other words, legal questions lack single right answers (Kress 2003).

Linguistic indeterminacy may trigger the use of certain rules of statutory interpretation. In English courts, statutes are firstly interpreted using the plain meaning of language (the Literal rule). Where the language of the statute is found to be obscure or ambiguous, courts may depart from the ordinary meaning of the text if its application leads to an absurd outcome (the Golden rule), or if the secondary meaning better advances the remedy of the targeted "mischief and defect" (the Mischief rule), or if the secondary meaning is favorable to the accused in a criminal case (the rule of lenity). To help resolve ambiguity, courts may consider the contextual circumstances and external evidence such as preparatory documents leading up to the legislation, and consult dictionaries or sometimes corpus data. These discretionary considerations may be exercised only if indeterminacy is identified, as stated by Lord Reid in Black-Clawson v Papierwerke (1975): "In the comparatively few cases where the words of a statutory provision are only capable of having one meaning, that is an end of the matter and no further enquiry is permissible."

Although rules of interpretations are ordinarily predicated on the certainty of the language of the law, judges are "generally astute to find the necessary 'ambiguity' which enabled them to interpret the document in proper context" in trying to avoid injustice (Lord Hoffmann in Kirin-Amgen $v$ Hoechst).

Legal translation, linguistic indeterminacy, legal multilingualism, and approaches to statutory interpretation are intricately related. The need for legal translation is driven by official language policies. The scope of linguistic indeterminacy seems to be expanded by legal bilingualism or multilingualism (hereafter "multilingualism" will be used as a cover term for both bilingualism and multilin-

1 An authenticated translation often loses the label of "translation" (and becomes "an authenticated text") in bilingual/multilingual jurisdictions so as to prevent its authority from being undermined. Since this paper focuses on legal translation rather than equal authenticity, I will not attempt to avoid using the label. 
gualism), under which not only intralingual but also interlingual indeterminacy ${ }^{2}$ may emerge from different versions of the law. While a monolingual text may often be read in more than one way and therefore may be ambiguous, discrepancies are also likely to arise when two clearly written, equally authentic language versions of the same statute are incoherent with each other. It is not difficult to imagine, however, that additional versions of the law may sometimes help resolve the ambiguities contained in one version.

Existing canons of interpretation were developed with the assumption that there is only one authentic text of the law; they may not be prepared to deal with out-and-out conflicts between authentic texts. As noted by Beaupré (1986: 1), when constructing a bilingual statute, "the question as to the ambiguity of the text may very possibly be resolved differently," and the Maxwellian rules of interpretation often become unproductive and irrelevant. How have approaches to statutory interpretation reacted to legal multilingualism? How are authenticated translations being read? Are intralingual indeterminacies dealt with in the same way in a bilingual jurisdiction as in a monolingual jurisdiction? How are the treatments of intralingual indeterminacies and interlingual indeterminacies different? Are there global trends across bilingual and multilingual jurisdictions? How would they impact upon legal translation? These are important questions to explore as multilingualism has become the norm in international law, and it is also becoming more common at the national level. Legal texts that are primary sources of law such as treaties, constitutions, and statutes and their authenticated translations, taken from various bilingual and multilingual jurisdictions, especially Canada, Hong Kong, and the EU, will be used as examples. I will show that although there are differences among the interpretative practices in these jurisdictions, a general trend emerges. Multilingualism not only brings in an additional reference text, but fundamentally shifts the norm of statutory interpretation, and the perceived relationship between the law and the texts that represent it. I will discuss how these should feed back into the preparation of multilingual texts by the legal translator. Via examining across jurisdictions how multilingual authentic texts are interpreted in courts, I shall build upon and expand Šarčević's (1997) position on a receiver-oriented approach to legal translation, and refute criticisms against the position. I argue that a converging approach in interpreting multilingual legislation and a revised conceptualization of the relationship between language and the law ought to impact on the theory and practice of legal translation.

2 Referring to textual discrepancies/inconsistencies. Both intralingual and interlingual indeterminacies are subtypes of linguistic indeterminacy. 


\section{Approaches to legal translation}

It is not difficult to spot a parallel between debates in statutory interpretation and translation theories, captured roughly by the dichotomy between "the letter" and "the spirit." While a judge may choose to adhere to the literal meaning of a piece of legislation or to what they believe is the purpose of the law or the intent of the lawmakers, the translator may also choose to take a more literal or a freer approach to the translation task. An act of interpretation is in fact a preliminary step of translation.

The dichotomy is a coarse one, for among translation theorists alone one may find diverse opinions regarding the kind of equivalence that may exist among texts (such as terminological, textual, formal, functional, dynamic, communicative, etc.). The distance between theory and practice in legal translation tends to be significant, given how the translation task involves not just a choice of style but a whole cluster of fine-grained decisions spanning from choosing the right words to pragmatic and discourse considerations.

The traditional approach to legal translation is founded on the principle of fidelity to the source text. Literal translation was the golden rule, especially for the translation of legislation (Didier 1990, cited in Šarčević 2000), as the letter of the law is seen as sacred. As Poon (2005: 315) as put it, although translation style might be more liberal today, the first consideration in legal translation is still "fidelity to the original text." Even today the UN Instructors for Translators also states that fidelity to the original text "must be the first consideration" in official translation (Šarčević 1997: 16).

In her seminal work, Šarčević (1997) proposes that fidelity should be given to the single legal instrument instead. She argues for a receiver-oriented approach to legal translation, holding that legal considerations must prevail in selecting translation strategies. She challenges Vermeer's functional approach to translation, reasoning that the approach disregards "the fact that legal texts are subject to legal rules governing their usage in the mechanism of the law" (2000: 2). Placing the presumption of equal intent above that of equal effect and equal meaning, she argues that a translator's primary task is to produce a text that expresses "the uniform intent of the single instrument" (1997: 73).

Her approach was challenged by Poon (2005) who argues that it is not easy for a translator to try to foresee how a text will be interpreted by the court and how the same legal effect might be achieved by the target text, especially given the indeterminacy of word meaning. According to her, translators "must endeavor to give a faithful translation closest to the meaning of the source text" by producing “a semantically and syntactically literal translation," and leave interpretation issues with the court (2005: 322). 
Coming from the other end of the spectrum and calling for a free, natural translation approach that respects the text's contextual foundations in the legal system and culture, Wolff (2011: 238) also criticizes Šarčević (1997)'s approach for it assumes that legal translators need to have legal knowledge, which to him poses a "practical impossibility," and it presumes that legal intent is fixed and discoverable, which is not a "sustainable" argument. He also complains that the freedom given to translators by her approach is only "illusory" given how they will be limited by the "meaning potential" of the text.

We will return to Šarčević's approach and its criticisms after examining at the receiver's end, how multilingual texts are being read in court, especially when indeterminacy arises. This task has only been attempted briefly in her original work (1997: 76-79). ${ }^{3}$ Some existing forensic linguistic works have looked at how translation and interpretation affect adjudication in a multilingual courtroom; the time is ripe to consider how statutory interpretation in court may bring insights into translation and interpretation work.

\section{Interpreting multilingual legislation}

Intralingual indeterminacy refers to uncertainties such as those created by ambiguity (semantic, syntactic, referential, pragmatic, etc.), vagueness, generality, and relativity. Interlingual indeterminacy arises when two texts do not completely correspond. Apart from inheriting potential intralingual indeterminacy from each of the authentic texts, bilingual legislation may also be interlingually indeterminate. When one language text of a bilingual legislation is indeterminate, discrepancies between texts would also arise, except in the very unlikely situation that the two language texts are indeterminate in exactly the same way. Although I shall attempt to analyze intralingual and interlingual indeterminacy separately, it should be noted that the phenomena often overlap significantly.

In bilingual jurisdictions, statutory interpretation typically starts with one language version of a statute. The other language version is brought up if an intralingual indeterminacy is discovered, if a discrepancy is alleged, or if the court simply wishes to confirm its interpretation of one text using the other authentic text. In some jurisdictions, routine comparisons between language versions are encouraged (e.g., in the bijural jurisdiction of Canada, or the multilingual WTO), even in the absence of an apparent discrepancy. The existence of more than one

3 1. Her discussion is restricted to Canadian cases. 2. She has included only two means of resolving ambiguities and textual inconsistencies. 3. She does not address wider interpretation trends across jurisdictions and consider the implications of them for legal translation. 
language text can be immensely helpful in resolving intralingual ambiguities; according to Beaupré, many cases would not have reached the courts "had the parties compared the two versions of the law in the first place" (1986: 2-3). In translation studies, Berman has also argued that "clarification is inherent in translation, to the extent that every translation comprises some degree of explication" (2000 [1985]: 289). However, at other times, bringing in another authentic text might lead to the discovery of an additional layer of uncertainty.

\subsection{Resolving intralingual indeterminacy}

\subsubsection{A comparative reading of the texts}

In jurisdictions in which bilingual texts are held to be equally authentic, an important assumption is that both language texts contain the same meaning. As in a monolingual jurisdiction, the starting point of interpretation is the ordinary meaning of the statutory texts. When the language version under examination is found to carry more than one possible meaning, one naturally turns to the other authentic text to see which of the possible meanings it is in agreement with. The shared meaning rule ${ }^{4}$ resolves indeterminacy by comparing both authentic texts and giving preference to the meaning which is common to them.

Semantic ambiguity in one text may be resolved by reference to the other authentic text. Section 9 of the Education Act 1998 of Ireland stipulates that schools shall promote the development of "Irish literature," a term which is ambiguous between literature in the Irish language only, or literature from Ireland, which may be written in Irish or English. It was suggested that the ambiguity may be resolved by referring to the Irish text as litriocht na hÉreann ('the literature of Ireland'), which encompasses literature written in languages other than Irish (Cárthaigh 2007).

The Canadian case of Tupper v. R. is an example of how the other authentic text may be used to clarify the semantic scope of a general expression. In this case, three screwdrivers, a flashlight, socks, nylon stockings, a crowbar, and a pair of woolen gloves with leather palms were found in the appellant's car. The

\footnotetext{
4 According to Bastarache et al. (2008), the shared meaning rule has two subtypes - The Ambiguity Shared Meaning Rule and the Breadth Shared Meaning Rule. The former, which applies when one of two versions is clear and the other ambiguous, determines that the clear one is likely to be the correct representation of the intention of Parliament. Where one version is broad and the other narrow, legislative intent does not prima facie suggest a choice between the two.
} 
Supreme Court had to decide whether under s. 295(1) of the Criminal Code ${ }^{5}$, possession of "any instrument for house-breaking" refers to an instrument ordinarily used for house-breaking, or any instrument capable of being used for house-breaking ${ }^{6}$. To clarify the meaning of the noun phrase, the Court referred to the French text of the Code, which reads "un instrument pouvant servir aux effractions de maisons," and concluded that the "French version makes the meaning clear" and that an instrument for house-breaking is one capable of being used for house-breaking.

The shared meaning has been used to confirm whether conjoined phrases had the same meaning or not. In R. v. Barnier, the Canadian Supreme Court had to decide whether the meaning of insanity contained in s. 16(2) the Criminal Code, defined as being incapable of "appreciating the nature and quality of an act" or "of knowing that an act is wrong," contains two distinct and separate tests. After consulting the dictionary definitions of terms used in each of the two language versions of the Code, the Court found that the meaning of "savoir" and "juger" in the French text corresponded with that of "know" and "appreciate" in the English text, and concluded that the two terms contained an important difference.

In a similar Canadian case of Kodellas v. Saskatchewan (Human Rights Commission), it was unclear to the Saskatchewan Court of Appeal whether the conjoined adjectives "appropriate and just" in s. 24(1) ${ }^{7}$ of the Canadian Charter of Rights and Freedoms denote one concept or two. It stated that "(t)o refer to only one language version may result in failure to properly ascertain the true meaning of the Constitution," and used a reading of the French text (containing the word "juste" and "convenable," which convey the senses of fairness and appropriateness respectively) to successfully clarify an indeterminacy that exists in the English text.

Although it is a default action to bring up the other authentic text where an intralingual indeterminacy is found, the application of the shared meaning rule is limited. The rule may be seen, at best, as an additional canon of interpretation

5 295. (1) Everyone who without lawful excuse, the proof of which lies upon him, has in his possession any instrument for house-breaking, vault-breaking or safe-breaking is guilty of an indictable offence and is liable to imprisonment for fourteen years.

6 The phrase "any instrument for house-breaking" is not lexically or structurally ambiguous, but it is vague in that it is a matter of degree how likely/frequently an object is used for housebreaking. The expression "an instrument ordinarily used for house-breaking" covers the prototypical members, whereas "any instrument capable of being used for house-breaking” includes both the prototypical and the less prototypical instances.

7 24. (1) Anyone whose rights or freedoms, as guaranteed by this Charter, have been infringed or denied may apply to a court of competent jurisdiction to obtain such remedy as the court considers appropriate and just in the circumstances. 
available in bilingual statutory interpretation. Most bilingual jurisdictions are reluctant to incorporate it as a written principle of statutory interpretation. When drafting the Vienna Convention on the Law of Treaties (VCLT) 1969, the International Law Commission (ILC) had decided against giving preference to a clearer text, a narrower text containing a more restricted meaning, or a meaning that is in agreement with all texts (the shared meaning rule), arguing that the decision should be left to the discretion of the court (Tabory 1980). It was pointed out that a common sense solution is not always the best solution, and in problematic cases, there may not exist any common meaning among the texts. Previous jurisprudence has not offered unequivocal guidance on the above solutions, and thus the VCLT, which is a codification of existing international customary law and not an innovation, did not include them. There was also the concern that to grant the comparison of texts the status of a canon of interpretation would imply that it was impossible to rely on a single text to interpret a multilingual treaty. The bilingual (and bijural) jurisdiction of Canada has similarly held that the shared meaning rule is not absolute, but has accepted a comparative reading of both official versions of the legislation as an initial step to bilingual statutory interpretation.

\subsubsection{A purposive and contextual approach}

In most bilingual and multilingual jurisdictions, the overriding consideration is whether the interpretation arrived at is consistent with the purpose and object of the law. Where there is a difference in the meaning of multilingual texts that the application of the general and supplementary rules of interpretation does not remove, the only guideline that the VCLT provides is that "the meaning which best reconciles the texts, having regard to the object and purpose of the treaty," shall be adopted (Article 33). Similarly, in Canada, the meaning of a statute should be construed according to the true spirit, intent and meaning of an enactment, and in a way that best ensures the attainment of its objects. Whatever common or dominant meaning is found in a bilingual or multilingual legislative provision, the court still has to determine whether it is consistent with legislative intention (Bastarache et al. 2008).

If the shared meaning is found to be absurd or otherwise inappropriate when tested against the entire context of the provision, the court may reject it. In Food Machinery Corp. v. Canada (Registrar of Trade Marks), the English text of the law contains two possible interpretations, and the French text supports only one of them. The Court rejected the shared meaning contained in the English and French texts of Section 26(2) of the Unfair Competition Act because this meaning is in 
conflict with the provision in Section 26(1), and held that the Parliament could not have intended such unreasonableness.

In Jones and Maheux v. Gamache, the Supreme Court of Canada had to determine whether "fonctionnaire de la Couronne" in the Exchequer Court Act refers to only a civil servant, which is the ordinary meaning of the expression in French, or whether it should be read to include a minister, which is embraced by the English equivalent "officer." Considering the context of the legislation, the court had decided that a "fonctionnaire" is a person fulfilling a public function and this primary meaning is wide enough to include a minister, refusing to let the French term cut down the broad meaning of the English equivalent.

\subsection{Resolving interlingual indeterminacy}

Interlingual indeterminacy is obviously a problem peculiar to bilingual jurisdictions, and is particularly tricky in jurisdictions that assume equal authenticity of all official texts of the law. One of the most common cases involves texts that contain supposedly equivalent terms of different semantic scope. In case of significant divergence, no meaning is shared between the language versions; not only is the other language text of little help in resolving the intralingual indeterminacy of a text, interlingual indeterminacy may raise the question of whether the meaning(s) contained in one text should be followed at all.

\subsubsection{A comparative reading of the texts}

In case of an alleged discrepancy between texts, the shared meaning rule may become relevant again. In Professional Institute of the Public Service of CanadaAircraft Operations Group v. Anti-Inflation Appeal Tribunal, the Canadian Federal Court of Appeal had to determine whether an unilateral action of the Treasury Board amounted to a "new compensation plan" within the meaning of subsection 44(1) of the Anti-Inflation Act, which exempted employees from a ceiling of salary increase contained in paragraph 43(1)(b), where "a new compensation plan was not entered into or established prior to October 14, 1975." Compensation plan is defined as "an arrangement for the determination and administration of the compensation of employees / une entente visant la détermination et l'administration de la rémunération d'employés.” Here the French term “entente," which refers to an agreement arrived at between consenting parties and excludes unilateral agreement offered by one party, has a more restricted meaning than the English term "arrangement" and was preferred as the shared meaning of the texts. 
Sometimes the court does not simply adopt one meaning of an ambiguous term and discard another. Courts may arrive at a blended meaning between two texts of the law that cannot be established by relying on either text alone. In Aeric Inc. v Canada Post Corp., it was not clear whether "the principle business" ("l'activité principale") refers to only profit-making activities as suggested by the English text, or a wider sense captured by the French text. The Court harmonized the meaning of the possible interpretations and concluded that the phrase may refer to non-profit making activities that were related to a business carried on by the person.

\subsubsection{Preferring one text over another}

Some bilingual jurisdictions expressly provide for one language text to prevail in case of discrepancy. However, even in these cases, the preference for a dominant text may not be an absolute principle. In Ireland, it has been suggested that preference for the Irish text is a canon of interpretation used at the discretion of the court (Cárthaigh 2007), and is usually applied only after attempts at reconciliation fail.

Although in jurisdictions that uphold the equal authenticity principle, courts generally avoid giving preference to one language text, it may de facto be done via the use of other canons of interpretation, based on legislative history such as the temporal order of enactment.

Canadian courts generally reject the distinction between "original" and "translation" in their bilingual legislation; however, legislative history is still sometimes relevant. In Klippert v. R., the English and French texts of s.659 of the Criminal Code define a "dangerous sexual offender" differently as a person who "has shown a failure to control his sexual impulses" or "a manifesté une impuissance à maîtriser ses impulsions sexuelles" (literally: has shown a lack of power to control). When the Code was amended in 1967, only the English version was altered (from "a lack of power to control" to "has shown a failure to control"), creating the discrepancy in meaning. Relying on legislative history, the Court upheld the meaning contained in the English version, since otherwise the meaning of the Parliamentary intervention would be undone. Although under s.10B of the Interpretation and General Clauses Ordinance (Cap.1), the Chinese and English texts of the law are equally authentic in Hong Kong, preference for the English text is systematically given. For 532 principal ordinances and around 1,000 pieces of subsidiary legislation, the Chinese text was only prepared and declared authentic subsequent to the English text. This allows courts to regard discrepancies as translation inaccuracies. HKSAR v. Lau San Ching may be used as an example. 
S.4(28) of the Summary Offences Ordinance (Cap.228) provided that the offence occurred where "Any person who without lawful authority or excuse ... does any act whereby ... obstruction, whether directly or consequentially, may accrue to a public place ..." However, the word "may" does not appear in the Chinese text. The meaning contained in the Chinese text is narrower, requiring an actual obstruction of a public place for proving the offence. However, the court disregarded the shared meaning and argued that where "the ordinance was initially enacted in English, the English text was the original official text and should be taken as more accurately reflecting the Legislature's intent at the time it was originally enacted and should take precedence over the Chinese text."

\subsubsection{A purposive and contextual approach}

Purpose is the overriding consideration in resolving interlingual indeterminacy. The case of Doré v. Verdun concerned the discrepancy in meaning between the term "disposition" in the French version of Article 2930 of Civil Code of Québec, and the equivalent term "stipulation" in the English version. The English term has a narrower, exclusively contractual connotation. The Canadian Supreme Court refused to be bound by the meaning shared by both language versions of the law, adopted an interpretation based on the French term and Parliamentary history, and argued that the interpretation is consistent with legislature's intention.

In reconciling multiple authentic texts, EU courts generally adopt a purposive (or teleological) approach to interpretation. In Fonden Marselisborg Lystbådehavn $v$ Skatteministeriet, French, English, Italian, Spanish, Portuguese, German, and Finnish versions of Article 13B(b) of the Sixth Council Directive have used a term for "vehicles" that covers general means of transport, ${ }^{8}$ while the Swedish, Dutch, Greek, and Danish equivalents have a more limited meaning, covering only landbased transport. There is then a case of interlingual lexical ambiguity. Although the Danish word kjøretøjer clearly refers to land-based transport on wheels, and this is the shared meaning of all language versions, the court held that "vehicles" used in that provision must be interpreted as covering all means of transport, by reference to the purpose and general scheme of the rules of which it forms a part - that VAT should be charged on all taxable transactions except the case of derogations expressly provided for, and thus the scope of derogations should be interpreted strictly.

8 In 13B(b)(2), "the letting of premises and sites for parking vehicles" is listed as an exception to the tax exemption laid down for the leasing and letting of immovable property. 


\section{A fundamental shift of focus}

Intralingual indeterminacy is dealt with differently in a monolingual versus a bilingual jurisdiction, given the other authentic text serving as an additional and important contextual element for interpretation. Interlingual indeterminacy is an additional source of linguistic indeterminacy that contributes to legal indeterminacy in a bilingual jurisdiction. Although intralingual and interlingual indeterminacy may potentially be resolved by comparing different language versions of a text, linguistic indeterminacy in a bilingual jurisdiction is often resolved by teleology, and not via the texts of the statute itself. The adherence to context and purpose is not a new approach to statutory interpretation, but the approach has taken on a novel dimension of meaning, functionality and significance in a bilingual or multilingual legal environment. The approach is attractive to bilingual and multilingual jurisdictions because it allows for the preservation of unity of the law, despite its potentially divergent representations.

In resolving serious interlingual indeterminacy, it is often difficult to avoid doing violence to the language of the enactment in one way or another, as the outcome of interpretation might not be what some of the authentic texts can reasonably be understood to mean. Difficulties as such have led the courts to move away from textualism, and fuelled a conceptualization of the law that is distant from the text that formulates it. Under this conceptualization, one can almost completely separate legal meaning from linguistic meaning, for one could argue that words may not be well chosen to represent the actual legal meaning. This is captured neatly by Kasirer (2008) who poses the question, "What if the legislature has no mother tongue, and is best thought of as thinking in no natural language at all?" Legal meaning is an abstract entity that may only be reached contextually and pragmatically by considering the purpose of the law. The source text is but one medium that attempts to represent this abstract entity. What then should the legal translator be translating from?

\section{Implications for legal translation}

As mentioned in the introduction of this paper, linguistic indeterminacy opens the door for discretionary considerations, which are sometimes needed to avoid injustice. Lord Oliver in Black-Clawson has said that "Ingenuity can sometimes suggest ambiguity or obscurity where none exists" (also cited in Charnock 2006). With bilingual texts, the amount of ingenuity needed for the task will be reduced to a minimum, as two language versions of a text are almost bound to contain differences, in terms of the semantic scope and connotation of words, or structure 
of sentences. With the multiplicity of authentic texts, a contextual and purposive approach to interpretation is not only licensed but often necessitated.

Bilingual legislation containing interlingual ambiguities arising from clearly written texts may be seen as an additional source of support for the legal indeterminacy thesis - two or more legally acceptable interpretations may be read from the texts of the law, each having solid support from one language version of the law, leading to different legal outcomes. Legal multilingualism and multilingualism have made it more defensible to depart from the text of the law. Not only may interpretative trends in bilingual and multilingual jurisdictions provide an apt opportunity to reflect upon approaches to statutory interpretation in their monolingual counterparts, they also constitute food for thought for the legal translator.

A revised conceptualization of the relationship between language and the law, and the distancing between legal meaning and linguistic meaning encourage some rethinking of the role of the legal translator, who would traditionally hold on to the source text as the primary basis of their work. Eugene Nida's model (Bassnett 2000), which sees translation as a process of decoding and recoding, does not seem to capture the dynamics that we have observed in legal translation, for there is uncertainty as to whether the source text or the outcome of decoding best represents the intended meaning. With the purpose of the law being the primary consideration in interpretation, it appears that the anchor of translation might as well be placed on the abstracted legal meaning, which admittedly may be harder to grasp than the meaning behind a solid text.

A purposive approach to statutory interpretation does not logically warrant any particular translation strategy in the preparatory process of the law, but one can see how it diminishes the value of textual fidelity that Poon (2005) advocates for and aligns itself with Šarčevićs (1997) receiver-oriented approach to translation, which aims to preserve the unity of the instrument. A literal translation that raises doubt will simply prompt the court to distance itself from the text and look for a purposive interpretation.

Traditional perspectives in translation either see translation as a derivative text, and/or an independent text (Koster 2002). Neither of these conceptualizations seems to appropriately describe the status of an authenticated translation of statutes. It is useful for the legal translator to become aware of how multilingual legal texts are increasingly read as a whole, with versions juxtaposed with each other, and therefore their work contributes to a part of a unitary instrument rather than creates a new representation of an existing instrument. They are not just producing a translation that contains legal information but a law, a law that is often not read on its own but along with other language versions by its direct receivers. 
Returning to criticisms from Wolff (2011) mentioned earlier, although textualists such as Judge Easterbrook ${ }^{9}$ (1992) would argue that the idea of a uniform intent is a legal fiction, Šarčević (1997) posits that drafters might make the purpose of the text clearer by using an informative title, including a preamble or a purpose clause. Moreover, the open texture of the law should not stop interpreters from looking for its purpose. The practice of parallel drafting should also help ease the concern, allowing for opportunities to listen to and communicate with the lawmakers and to clarify confusions and ambiguities at the drafting stage. It is difficult to take seriously Wolff's complaint that the translator only has "illusory" freedom; reasonable constraints are simply desirable from a legal perspective. Translators are not legislators and they may actively contribute their expertise by ascertaining legislative intentions and figuring out how best to render them in the translation during the parallel drafting process. In legal translation, the opposite of literalism is not free translation, but the spirit of the law.

It is true that the burden on the translator might be heavier than before, in a similar way to how judges are now expected to be able to read and compare multilingual texts in order to ascertain a unified meaning. Legal knowledge on the part of the translator would be useful, even though that alone does not guarantee anyone (lawyers included) the ability to predict the legal meaning of a text that a court will arrive at. Legal translation may in a way be seen as interdisciplinary work, and acquiring knowledge across two academic disciplines is not unrealistic, in the same way as how many forensic linguists have dual qualifications in law and linguistics, and how lawyers specializing in medical malpractice often have some medical knowledge.

To conclude, I defend Šarčević’s (1997) receiver-oriented approach to legal translation by examining how authenticated translations are being read in court. I argue that conceptualization of the relationship between language and the law in bilingual and multilingual jurisdictions is being shifted and this ought to impact upon translation theories and practice. Within the domain of legal translation, the idea that translation is a process of interlingual transfer might need to be revised, and the boundary between the translator and the draftsman is becoming blurred. Stronger collaboration between the translator and the legislator in the drafting process, and a better appreciation of the judiciary's interpretation approaches by legal translators, should illuminate the future of legal translation.

9 He wrote, “[T] he concept of 'an' intent for a person is fictive and for an institution hilarious. A hunt for this snipe liberates the interpreter, who can attribute to the drafters whatever 'intent' serves purposes derived by other means." 
Acknowledgment: This research (code HKU 747812H) has been generously supported by the RGC General Research Fund.

\section{References}

Bassnett, Susan. 2000 [1980]. Translation studies. New York: Routledge.

Bastarache, M., N. Metallic, R. Morris \& C. Essert. 2008. The law of bilingual interpretation. Toronto: LexisNexis.

Beaupré, Michael. 1986. Interpreting bilingual legislation, 2nd edn. Toronto: Carswell.

Berman, Antoine. 2000 [1985]. Translation and the trials of the foreign, Lawrence Venuti (trans.). In L. Venuti (ed.), The translation studies reader, 284-297. New York: Routledge.

Cárthaigh, Daithí Mac. 2007. Interpretation and construction of bilingual laws: A Canadian lamp to light the way? Judicial Studies Institute Journal 2. 211-228.

Charnock, Ross. 2006. Clear ambiguity: The interpretation of plain language in English legal judgments. In A. Wagner \& S. Cacciaguidi (eds.), Legal language and the search for clarity (Linguistic Insights 37), 65-103. Bern: Peter Lang.

Easterbrook, Frank H. 1992. Some tasks in understanding law through the lens of public choice. International Review of Law and Economics 12. 284.

Kasirer, Nicolas. 2008. Foreword. In M. Bastarache, N. Metallic, R. Morris \& C. Essert, The law of bilingual interpretation, $\mathrm{v}$-ix. LexisNexis.

Koster, Cees. 2002. The translator in between texts: On the textual presence of the translator as an issue in the methodology of comparative translation description. In Alessandra Riccardo (ed.), Translation studies: Perspectives on an emerging discipline, 24-37. Cambridge: Cambridge University Press.

Kress, Kenneth, J. 2003. Legal indeterminacy. In Dennis Patterson (ed.), Philosophy of law and legal theory, 253-291. Oxford: Blackwell.

Poon, Wai Yee Emily. 2005. The cultural transfer in legal translation. International Journal for the Semiotics of Law 18. 307-323.

Šarčević, Susan. 1997. New approach to legal translation. The Hague: Kluwer Law International.

Šarčević, Susan. 2000. Legal translation and translation theory: A receiver-oriented approach. http://www.tradulex.com/Actes2000/sarcevic.pdf (accessed 26 April 2014).

Tabory, Mala. 1980. Multilingualism in international law and institutions. Alphen aan den Rijn: Sijthoff \& Noordhoff.

Wolff, Leon. 2011. Legal translation. In K. Malmkjer \& K. Windle (eds.), The Oxford handbook of translation studies, 228-242. Oxford: Oxford University Press.

\section{Cases cited}

Aeric Inc. v Canada Post Corp. [1985] 16 D.L.R. (4th). 686

Black-Clawson International Ltd v Papierwerke Waldhof-Aschaffenburg AG [1975] AC 591, HL(E)

Doré v. Verdun (City), [1997] 2 S.C.R. 862.

Food Machinery Corp. v. Canada (Registrar of Trade Marks) [1946] 2 D. L. R. 258 (Ex. Ct.)

Fonden Marselisborg Lystbådehavn v Skatteministeriet [2005] ECR I-1527 Case C-428/02 
Jones and Maheux v. Gamache [1968] 7 D. L. R. (3d) 316 (S.C.C.)

HKSAR v. Lau San Ching MA No 98 of 2002.

Klippert v. R. [1967] S. C. R. 822

Kirin-Amgen v Hoechst 2004 UKHL 46.

Kodellas v. Saskatchewan (Human Rights Commission) [1989] 60 D.L.R. (4th) 143 (Sask. C. A.)

Professional Institute of the Public Service of Canada - Aircraft Operations Group v. Anti-

Inflation Appeal Tribunal [1978] 2 F. C. 284 (C.A.)

R. v. Barnier [1980] 1 S.C.R. 1124

Tupper v. R. [1967] S. C. R. 589.

\section{Bionote}

Janny HC Leung (b. 1980) is an associate professor at the University of Hong Kong 〈janny@cantab.net〉. Her research interests include the intersection between language and the law, especially legal multilingualism and language rights. Her publications include "On the edge of reason: Law at the borderline" (2012); "Statutory interpretation in multilingual jurisdictions: Typology and trends" (2012); "Judicial discourse in Cantonese courtrooms in postcolonial Hong Kong: The judge as a godfather, scholar, educator, and scolding parent" (2013); and "Translation equivalence as a legal fiction" (2013). 